\title{
Fundamental Indexation For Global Equities: Does Firm Size Matter?
}

\author{
Heng-Hsing Hsieh, PhD, CFA, University of the Western Cape, South Africa \\ Kathleen Hodnett, PhD, University of the Western Cape, South Africa \\ Paul van Rensburg, PhD, University of Cape Town, South Africa
}

\begin{abstract}
Market capitalization is often used as the weighting methodology for broad market indexes to reflect the performances of large established firms in the market. The market capitalization of a firm is a price-sensitive measure of firm size that self-adjusts to reflect the firm's intrinsic value in an efficient capital market. In the presence of investor overreaction, the price-sensitive capweighted indexes cease to be mean-variance efficient in that they overweigh overvalued assets and under weigh undervalued assets. Fundamental indexation, proposed by Arnott, Hsu and Moore (2005), argue that fundamental values of a firm such as book value, revenues and earnings are price-insensitive, and hence are not subject to the systematic overshooting of asset prices through noise trading. The aim of this paper is to test whether fundamental-weighted indexes are more mean-variance efficient proxies for large established firms in the global equity market compared to cap-weighted indexes over an extensive 18-year period from 1991 to 2008. Test results show that fundamental-weighted indexes outperform cap-weighted indexes over two sub-periods as well as the overall examination period, during an expansionary market and in turbulent times. A strong negative relationship between the degree of index concentration and the index performance is detected for cap-weighted indexes while no such relationship is detected for the fundamentalweighted indexes. Our results suggest that price-insensitive fundamental-weighted indexes are more mean-variance efficient proxies for the performances of large firms for global equities relative to cap-weighted indexes. By removing the price-element in measuring firm size, the small firm anomaly is not present in fundamental-weighted indexes.
\end{abstract}

Keywords: Size Effect; Market Capitalization; Cap-Weighted Index; The Efficient Market Hypothesis; Small Firm Anomaly; Global Equity Market; Portfolio Rebalancing; Fundamental Indexation

\section{INTRODUCTION}

odern portfolio theory (MPT) postulates that in an efficient capital market, the market
capitalization of any asset accurately reflects its intrinsic worth, relative to other assets in the
market portfolio. Market capitalization has become the standard indication of firm size in financial markets. Broad equity market indexes such as the Standard \& Poor (S\&P) 500 Index in the United States of America (U.S.) and the All-Share Index in South Africa also estimate constituent weights based on their respective market capitalizations. Tracking the performance of a cap-weighted index incurs low rebalancing costs as the weights of the constituents in the index are self-adjusted through their respective market prices. The applications of the capweighted indexes are not without criticism. Due to their price-sensitive nature, the cap-weighted indexes cease to be mean-variance efficient in the presence of investor overreaction. In a market where investors overreact to the arrival of new information, systematic overshooting of asset prices result in cap-weighted indexes incorporating more overvalued assets and less undervalued assets (Arnott, Hsu and Moore, 2005). Noise Trading based on information that is already reflected in the asset price introduces unnecessary volatility without contributing to the fair valuation of the asset. The more prices fluctuate independently of the changes in the fundamentals, the greater the drag in the cap-weighted indexes (Hsu and Campollo, 2006). Arnott et al (2005) propose the use of price-insensitive measures of firm size such as book value, revenue and cash flow that are exempt from inefficient capital market pricing. These measures reflect the fundamentals underlying the firm's intrinsic value. Fundamental indexes formed by these measures are better reflections of the performance of large established firms in capital markets. 
Motivated by the argument of potential inefficiencies associated with cap-weighted indexes, we investigate the risk-adjusted performances of fundamental-weighted indexes relative to that of the cap-weighted indexes in the global equity market over the examination period from 1991 to 2008 . We construct fundamental-weighted indexes using the average values of trailing 5-year book value, earnings, dividends, sales and cash flow as the indication of firm size based on a monthly rebalancing method. On the other hand, the cap-weighted indexes are constructed using market capitalization as an indication of firm size. We investigate the effect of index concentration on index performance by forming indexes with $200,100,50$ or 30 constituents respectively. If investor overreaction is present in the global equity market, we would expect more concentrated cap-weighted indexes to underperform less concentrated cap-weighted indexes due to noise trading. Such effect is not expected to be present amongst fundamental-weighted indexes due to their price-insensitive nature. Observing the risk-return characteristics of different size proxies provides insight into the influences of different firm size measures for pricing global equities.

\section{LITERATURE REVIEW}

The market capitalization of a firm is a price-sensitive measure which self-adjusts to incorporate the dissemination of information relating to the efficient pricing of a firm's stock. As a result, investors have no preference over firms with different sizes and investment strategies formed by firm size alone would not yield abnormal profits under the notion of the efficient market hypothesis (EMH). This proposition is first challenged by Banz (1981) who finds that small firms outperform large firms using market capitalization as a measure of firm size on the New York Stock Exchange (NYSE) over the examination period from 1936 to 1975. Evidence of a size effect is also documented by Brown, Kleidon and Marsh (1983) on the NYSE over the examination period from 1969 to 1979 as well as Bauman, Conover and Miller (1998) who conducts studies in Europe, Australasia and Far East (EAFE) regions as well as Canada over the examination period from 1986 to 1996. When market capitalization is incorporated in the 3-factor model of Fama and French (1993), it is found that the factor related to firm size statistically significantly contributes to the explanation of portfolio returns formed by different investment styles. Arnott et al (2005) promote the use of fundamental indexes as proxies to represent the performance of large firms in the capital market. Fundamental indexes are price-insensitive and hence should not exhibit the size effect documented in empirical literature. Siegel (2003) argues that fundamental indexes provide investors protection against the impact of speculative bubbles. Speculative bubbles such as the tulip bubble in the $17^{\text {th }}$ century or the technology bubble in the late 1990s are created by irrational investors who continuously bid up prices in the hope that the fundamentals would eventually justify their prices. Contrasting the EMH which regards all price increases to be justifiable, the weight of a constituent in a fundamental index does not increase with its price until it is proven to be fundamentally viable.

Arnott et al (2005) employs book value, cash flow, sales, employment and dividends to construct fundamental-weighted indexes of 1,000 companies in the U.S. equity market over a 43-year period from 1962 through 2004. They find that the returns produced by the fundamental indexes outperform both the S\&P 500 Index and the cap-weighted benchmark constructed from the same sample statistically significantly. The sales-weighted index achieves the highest annual geometric return of $12.91 \%$ over the examination period, which is $2.38 \%$ higher than the S\&P 500 Index (10.53\%), and 2.56\% higher than the cap-weighted benchmark (10.35\%). Arnott et al (2005) further construct a fundamental-weighted composite index that includes book value, cash flow, sales and dividends jointly to provide a more accurate assessment of the firm size of the sample stocks. The average values of the four attributes are used as the score to determine the relative weights of the constituents in the composite. The results indicate that the fundamental composite index outperforms the S\&P 500 Index and the cap-weighted benchmark by $1.94 \%$ and $2.12 \%$ per annum respectively. When the performance of the respective indexes are evaluated on a risk-adjusted basis, it is found that the fundamental indexes and the fundamental composite index offer better returns with more or less similar levels of volatility as the cap-weighted benchmark. With the exception of the dividend-weighted index, the fundamental indexes and the fundamental composite index achieve more than $50 \%$ for their information ratios over the examination period. The fundamental indexes and the fundamental composite index are also more liquid compared to the cap-weighted benchmark in that their portfolio concentration ratios are lower and portfolio turnover rates are higher than the cap-weighted alternative. When the relative performances of the indexes are evaluated over the sub-periods, it is found that the underperformance of the capweighted benchmark relative to that of the fundamental indexes are robust across different phases of the business cycle and different interest rate regimes. 
Estrada (2006) extends the research of fundamental indexation to international capital markets with an additional objective of determining whether there exist additional benefits of international diversification for fundamental-weighted global equity indexes over the examination period from 1973 to 2005 . The 16 countries that comprise the research sample include Australia, Austria, Belgium, Canada, Denmark, France, Germany, Hong Kong, Ireland, Italy, Japan, Netherlands, Singapore, South Africa, the United Kingdom and the United States of America. A dividend yield-weighted fundamental index is constructed from the equity market indices of the 16 countries in the sample. The benchmarks used to evaluate the performance of the dividend yield-weighted index include the DataStream World Market Index and the cap-weighted composite of the 16 equity market indexes. The results indicate that the dividend yield-weighted index outperforms the benchmarks in terms of the cumulative returns over the examination period, with slightly higher monthly volatility, but slightly lower beta than the capweighted benchmark. The dividend yield-weighted index also outperforms the benchmarks on a risk-adjusted basis in that it achieves a higher return-to-volatility ratio, a lower worst month return and a higher best month return compared to the benchmarks. Although the dividend yield-weighted index appears to weigh the component country indexes more evenly than the cap-weighted index, no significant improvement in portfolio volatility is found in the study. Estrada (2006) concludes that while fundamental-weighted indexes appear to be more mean-variance efficient than cap-weighted indexes, no further international diversification benefits can be explored through fundamental indexation of global indices.

Kaplan (2008) criticizes the merits of fundamental indexation in that fundamental indexation inevitably introduces weighting errors by ignoring the future prospects of the firm contained in the market price. By allocating less weight to stocks that are highly priced, fundamental indexes might be just an alternative way to incorporate the value bias into the portfolio. In the opinion of Arnott (2005), fundamental indexation is not just another way of constructing value indices since it enjoys the benefits offered by investing in small caps and value stocks and simultaneously avoids the capitalization bias inherent in large caps and growth stocks whose prices are overinflated as a result of noise trading. Hsu and Campollo (2006) also argue that fundamental indexation has the ability to under weigh stocks that are not growing their fundamentals, which is far from simple value investing. In addition, value indexes are generally not well diversified and do not provide broad market participation. Hsu and Campollo (2006) examine the performances of the U.S. fundamental indexes over the period from 1979 to 2004. They find that the fundamental indexes outperform their respective Russell value indexes. The fundamental indexes also outperform the cap-weighted S\&P 500 Index during bull markets and expansionary economic environments, which are not achieved by the Russell value indexes.

\section{RESEARCH DATABASE}

To ensure that the stocks in major sectors in the global equity market are covered, the Dow Jones (DJ) Sector Titans Composite Index is employed as the database. The DJ Sector Titans Composite Index consists of the largest 30 international equities by market capitalization from each of the 19 second-tier sectors defined by the Industry Classification Benchmark (ICB). These sectors include automobiles and parts, banks, basic resources, chemicals, construction and materials, financial services, food and beverages, health care, industrial goods and services, insurance, media, oil and gas, personal and household goods, real estate, retail, technology, telecommunication, travel and leisure and utilities. The monthly U.S. dollar-denominated total return index, stock price, market capitalization, book value, earnings, dividends, gross sales and net cash flow for the constituents comprising the DJ Sector Titans Composite Index are extracted from DataStream International as of 30 June 2010 for the examination period from 01 January 1991 to 31 December 2008. The countries covered by this composite at the time of data extraction include Australia, Germany, Belgium, Brazil, Canada, Denmark, Spain, Finland, France, Greece, Hong Kong, Ireland, Italy, Japan, Korea, Luxembourg, Mexico, Netherlands, Norway, Portugal, South Africa, Sweden, Singapore, Switzerland, Taiwan, the United Kingdom and the United States of America.

To ensure the sufficient liquidity in the database, only the top 300 stocks measured by market capitalization in each month of the examination period are used to construct size-based indexes. This selection is in line with the research objective of identifying the most suitable large firm proxy for global equities. The effect of survivorship bias is also mitigated in this selection since large firms are less likely to be non-survivors. Look-ahead bias does not affect the results of this research since DataStream International only records data as the information becomes publicly available. 


\section{DESCRIPTIVE STATISTICS AND METHODOLOGY}

We construct four monthly-rebalanced cap-weighted indexes that are comprised of the top 200, 100, 50 and 30 stocks in terms of the market capitalization. In the same manner we construct four monthly-rebalanced fundamental-weighted indexes that are comprised of the top 200,100, 50 and 30 stocks in terms of the average values of the 5-year trailing fundamental attributes. The fundamental attributes employed to develop fundamentalweighted indexes include book value, earnings after tax, dividends, sales and cash flows. The purpose for the use of trailing average values is adapted from Arnott et al (2005) to avoid the substantial volatility of the year-on-year data, which reduces monthly portfolio turnover and the rebalancing costs. For non-dividend paying firms, only the average values of the remaining four attributes are computed to take into account the argument of Arnott et al (2005) that non-payment of dividends may not constitute to weak fundamentals of the firms. The weight of the $i$ th constituent in index $X$ for month $t$ is calculated using Equation 1:

$$
w_{X i, t}=\frac{A_{i, t}}{\sum_{j=1}^{n_{X}} A_{j, t}}
$$

Where:

$A_{i, t} \quad$ is the value of the attribute of the $i$ th constituent in index $X$ developed from attribute $A$ at the beginning of month $t . A$ is the market capitalization for cap-weighted indexes or the average trailing fundamental values for fundamental-weighted indexes; and

$n_{x} \quad$ is the number of constituents in index $X . n_{x}$ takes on value of $200,100,50$ or 30.

One of the major advantages of cap-weighted indexation is that the constituents' weights are self-adjusted through stock price movements. The relatively lower trading costs associated with cap-weighted indexes have to be taken into account when comparing their performances with the fundamental-weighted indexes. We first compute the percentage portfolio turnover for index $X$ in month $t$ using Equation 2:

$$
\text { turnover } r_{X, t}=\sum_{i=1}^{K_{t}}\left|\Delta w_{X, i, t}\right|
$$

Where:

$\Delta w_{X, i, t}=w_{X, i, t}-\left(w_{i, t-1} \times \frac{1+r_{i, t-1}}{1+r_{X, t-1}}\right) ;$

$K_{t} \quad$ is the total number of stocks in the research sample in month $t$;

$w_{X, i, t} \quad$ is the weight of stock $i$ in index $X$ for month $t$;

$w_{, i, t-1} \quad$ is the weight of stock $i$, at the end of month $t-1$ after its price movement in month $t-1$ just before the rebalancing at the beginning of month $t$; and

$r_{i, t-1} \quad$ is the returns of stock $i$; and $r_{x, t-1}$ is the returns of index $X$ in month $t-1$.

The portfolio turnover depicted by Equation 2 indicates the impacts of both buying and selling activities for an index. When $\Delta w_{i, t}$ is positive, additional acquisition of stock $i$ is required. By the same token, a negative $\Delta w_{i, t}$ signals that a reduction in the holding of stock $i$ in the index is required. The updating of the weights for sample stocks in an index depends on their performances relative to the performance of the index. Holding all else constant, an index constituent gains weight in the index if it performs better than the index in the previous month. This selfadjustment effect is taken into account when computing the monthly portfolio turnover using Equation 2. Based on this equation, the average monthly percentage index turnover is estimated using Equation 3: 
Avg. Monthly Percentage Turnover ${ }_{X . m .}=\frac{\sum_{t=1}^{T} \text { turnover }_{X, t}}{T}$

In order to gauge the impact of index rebalancing on the performances of the index, the implicit transaction costs incurred through rebalancing are deducted from the return of the index monthly to estimate the monthly costadjusted return as shown in Equation 4. The transaction costs are assumed to be $2 \%$ of the rebalanced amount in each month:

Cost - Adjusted $r_{X, t}=r_{X, t}-\left(2 \% \times\right.$ turnover $\left._{X, t}\right)$

The maximum constituent weight is capped at $10 \%$ to prevent the indexes from being unduly concentrated. Three risk-adjusted performance measures employed to evaluate the indexes are the Sharpe ratio, the Treynor measure and Jensen's alpha. The performances of the indexes are evaluated over the examination period from 01 January 1991 to 31 December 2008 and two sub-periods: 01 January 1991 to 31 December 1999 and 01 January 2000 to 31 December 2008 respectively. Using the 3-month U.S. Treasury bill as the proxy for the risk-free asset, the Sharpe Ratio of index $X$ is computed using Equation 5:

Sharpe $_{X}=\frac{R_{X}-R_{f}}{\sigma_{X}}$

Where:

$R_{X} \quad$ is the return on index $X$ over the evaluation period;

$R_{f} \quad$ is the yield on the 3-month U.S. Treasury bill over the evaluation period; and

$\sigma_{X} \quad$ is the standard deviation of return on the index $X$ over the evaluation period.

The Sharpe ratio measures the reward for bearing total risk (measured by the standard deviation of returns).

The Treynor measure and Jensen's alpha, on the other hand, adopts the beta coefficient to measure systematic risk inherent in the index being evaluated. The beta coefficient is estimated using time-series regression as shown in Equation 6, where the Morgan Stanley Capital International (MSCI) World Index is employed as the market proxy:

$R_{X, t}-R_{f, t}=\alpha_{X}+\beta_{X} \times\left(R_{m, t}-R_{f, t}\right)+\varepsilon_{X, t}$

Where:

$R_{X, t} \quad$ is the return on index $X$ in month $t$;

$R_{f, t} \quad$ is the yield on the 3-month U.S. Treasury bill in month $t$;

$R_{m, t} \quad$ is the U.S. dollar-denominated total return on the MSCI World Index in month $t$;

$\beta_{X} \quad$ is the beta coefficient of the regression; and

$\varepsilon_{X, t} \quad$ is the regression residual in month $t$.

The regression intercept $\alpha_{X}$ is Jensen's alpha that indicates the abnormal return earned above the required risk-adjusted return based on the capital asset pricing model (CAPM). Using the beta coefficient as the measure of systematic risk, the Treynor ratio is computed using Equation 7:

Treynor $_{X}=\frac{R_{X}-R_{f}}{\beta_{X}}$ 


\section{EMPIRICAL FINDINGS}

Table 1 tabulates the basic risk-return performance statistics for the (1) MSCI World Index, the capweighted (CAP) indexes ((2), (3), (4) and (5)) and the fundamental-weighted (FNDL) indexes ((6), (7), (8) and (9) respectively). The first sub-period (1991 to 1999) represents an expansionary market. All of the indexes earn positive returns in the first sub-period. By contrast, the second sub-period (2000 to 2008) represents a contraction period with the crash of the information technology (I.T.) bubble in the early 2000s and the sub-prime crisis that led to the financial market crash in late 2008. All of the indexes earn negative returns in the second sub-period. The examination of the cost-adjusted returns of the cap-weighted indexes in Panel A of Table 1 reveals that the return of the cap-weighted indexes deteriorates as the degree of portfolio concentration increases in all examination periods. This result suggests that the small firm effect is inherent in the global equity market over the examination periods. This phenomenon is not detected for the fundamental-weighted indexes.

Comparing the returns of the cap-weighted indexes to that of the fundamental-weighted indexes with the same number of constituents shows that all the fundamental-weighted indexes outperform their cap-weighted counterparts in all examination periods. All cap-weighted indexes earn less return compared to the MSCI World Index over all examination periods. By contrast, the fundamental-weighted indexes earn comparable return over the first sub-period, but make substantially less loss over the second sub-period compared to the MSCI World Index. The resilient nature of the fundamental-weighted indexes is noted during turbulent times.

In terms of the average monthly portfolio turnover demonstrated in Panel D of Table 1, the $10 \%$ cap placed on the maximum constituent weight introduces some portfolio turnover to the cap-weighted indexes. Although the cap-weighted indexes are subject to considerably lower portfolio rebalancing requirements and hence considerably lower transaction costs, they also earn considerably lower returns compared to their fundamental-weighted index counterparts.

Table 1: Basic Performance Statistics of Size Indexes

\begin{tabular}{|c|c|c|c|c|c|c|c|c|c|}
\hline Period & $\begin{array}{c}\text { (1) } \\
\text { MSCI } \\
\text { World }\end{array}$ & $\begin{array}{c}(2) \\
\text { CAP } \\
200\end{array}$ & $\begin{array}{c}\mathbf{3}) \\
\text { CAP } \\
\mathbf{1 0 0}\end{array}$ & $\begin{array}{c}(4) \\
\text { CAP } \\
50\end{array}$ & $\begin{array}{c}\mathbf{( 5 )} \\
\text { CAP } \\
\mathbf{3 0}\end{array}$ & $\begin{array}{c}\text { (6) } \\
\text { FNDTL } \\
200\end{array}$ & $\begin{array}{c}(7) \\
\text { FNDTL } \\
\mathbf{1 0 0}\end{array}$ & $\begin{array}{c}\text { (8) } \\
\text { FNDTL } \\
50\end{array}$ & $\begin{array}{c}(9) \\
\text { FNDTL } \\
30\end{array}$ \\
\hline \multicolumn{10}{|c|}{ Panel A Annualized Cost-Adjusted Return } \\
\hline $1991-1999$ & $15.67 \%$ & $13.16 \%$ & $12.66 \%$ & $11.51 \%$ & $10.84 \%$ & $17.04 \%$ & $17.01 \%$ & $16.98 \%$ & $17.19 \%$ \\
\hline $2000-2008$ & $-2.69 \%$ & $-4.62 \%$ & $-6.10 \%$ & $-7.29 \%$ & $-8.95 \%$ & $-0.57 \%$ & $-0.69 \%$ & $-0.68 \%$ & $-0.70 \%$ \\
\hline $1991-2008$ & $6.10 \%$ & $3.89 \%$ & $2.86 \%$ & $1.68 \%$ & $0.46 \%$ & $7.88 \%$ & $7.80 \%$ & $7.79 \%$ & $7.87 \%$ \\
\hline \multicolumn{10}{|c|}{ Panel B Annualized Standard Deviation } \\
\hline $1991-1999$ & $12.56 \%$ & $13.89 \%$ & $14.68 \%$ & $15.22 \%$ & $15.18 \%$ & $13.74 \%$ & $14.01 \%$ & $14.34 \%$ & $14.53 \%$ \\
\hline $2000-2008$ & $16.25 \%$ & $16.11 \%$ & $16.15 \%$ & $15.98 \%$ & $15.98 \%$ & $17.20 \%$ & $17.36 \%$ & $17.37 \%$ & $17.40 \%$ \\
\hline $1991-2008$ & $14.69 \%$ & $15.20 \%$ & $15.62 \%$ & $15.79 \%$ & $15.80 \%$ & $15.70 \%$ & $15.90 \%$ & $16.05 \%$ & $16.16 \%$ \\
\hline \multicolumn{10}{|c|}{ Panel C Beta Coefficient } \\
\hline $1991-1999$ & 1.00 & 1.01 & 1.05 & 1.07 & 1.04 & 0.84 & 0.83 & 0.82 & 0.80 \\
\hline $2000-2008$ & 1.00 & 0.98 & 0.97 & 0.93 & 0.90 & 0.97 & 0.97 & 0.95 & 0.94 \\
\hline $1991-2008$ & 1.00 & 0.99 & 1.00 & 0.98 & 0.95 & 0.92 & 0.92 & 0.90 & 0.89 \\
\hline \multicolumn{10}{|c|}{ Panel D Average Monthly Portfolio Turnover } \\
\hline $1991-1999$ & ------- & $2.54 \%$ & $2.40 \%$ & $2.61 \%$ & $2.82 \%$ & $6.25 \%$ & $5.98 \%$ & $5.82 \%$ & $5.60 \%$ \\
\hline $2000-2008$ & -------- & $1.72 \%$ & $1.83 \%$ & $2.04 \%$ & $2.26 \%$ & $6.34 \%$ & $6.22 \%$ & $6.04 \%$ & $5.81 \%$ \\
\hline $1991-2008$ & -------- & $2.13 \%$ & $2.11 \%$ & $2.32 \%$ & $2.54 \%$ & $6.29 \%$ & $6.10 \%$ & $5.93 \%$ & $5.70 \%$ \\
\hline
\end{tabular}

The returns on the fundamental-weighted indexes are slightly more volatile compared to the MSCI World Index as shown by the standard deviations in Panel B of Table 1. The standard deviations of the cap-weighted indexes are roughly in line with the standard deviation of the MSCI World Index. The beta coefficients displayed in Panel C of Table 1 indicate that the beta coefficients for the cap-weighted indexes are slightly higher than average during the expansionary market and slightly lower than average during market contraction. On the other hand, the beta coefficients for the fundamental-weighted indexes are lower than average over all examination periods. 
Table 2 demonstrates the risk-adjusted performances of the respective size indexes. Using standard deviation as the relevant measure of risk, fundamental-weighted indexes outperform the MSCI World Index in all examination periods in terms of the Sharpe ratios demonstrated in Panel A of Table 2. By contrast, the cap-weighted indexes underperform the MSCI World Index in all examination periods in terms of the Sharpe ratio. Similar results are obtained when the beta coefficient is employed as the relevant risk measure in terms of the Treynor ratio (refer to Panel B of Table 2) and Jensen's alpha (refer to Panel C of Table 2). The Sharpe ratios, Treynor ratios and Jensen's alpha for all the cap-weighted indexes are negative in the overall examination period. Once again, the negative relationship between the degree of portfolio concentration and risk-adjusted performance for the capweighted indexes is detected. On the other hand, no distinctive difference in risk-adjusted performance is noted for fundamental indexes with different degrees of portfolio concentration.

Table 2: Risk-Adjusted Performance Statistics of Size Indexes

\begin{tabular}{|c|c|c|c|c|c|c|c|c|c|}
\hline Period & $\begin{array}{c}(1) \\
\text { MSCI } \\
\text { World }\end{array}$ & $\begin{array}{c}(2) \\
\text { CAP } \\
200\end{array}$ & $\begin{array}{c}(3) \\
\text { CAP } \\
100\end{array}$ & $\begin{array}{c}(4) \\
\text { CAP } \\
50\end{array}$ & $\begin{array}{c}\mathbf{( 5 )} \\
\text { CAP } \\
\mathbf{3 0}\end{array}$ & $\begin{array}{c}(6) \\
\text { FNDTL } \\
200\end{array}$ & $\begin{array}{c}(7) \\
\text { FNDTL } \\
100\end{array}$ & $\begin{array}{c}(8) \\
\text { FNDTL } \\
50\end{array}$ & $\begin{array}{c}\text { (9) } \\
\text { FNDTL } \\
\mathbf{3 0}\end{array}$ \\
\hline \multicolumn{10}{|c|}{ Panel A Annualized Sharpe Ratio } \\
\hline $1991-1999$ & 0.872 & 0.607 & 0.540 & 0.446 & 0.402 & 0.896 & 0.877 & 0.854 & 0.857 \\
\hline $2000-2008$ & -0.354 & -0.477 & -0.567 & -0.648 & -0.752 & -0.211 & -0.216 & -0.216 & -0.216 \\
\hline $1991-2008$ & 0.150 & 0.000 & -0.066 & -0.140 & -0.217 & 0.254 & 0.245 & 0.242 & 0.246 \\
\hline \multicolumn{10}{|c|}{ Panel B Annualized Treynor Ratio } \\
\hline $1991-1999$ & 0.109 & 0.083 & 0.076 & 0.064 & 0.059 & 0.147 & 0.147 & 0.149 & 0.156 \\
\hline $2000-2008$ & -0.058 & -0.078 & -0.095 & -0.112 & -0.134 & -0.037 & -0.038 & -0.039 & -0.040 \\
\hline $1991-2008$ & 0.022 & 0.000 & -0.010 & -0.023 & -0.036 & 0.044 & 0.043 & 0.043 & 0.045 \\
\hline \multicolumn{10}{|c|}{ Panel C Annualized Jensen's Alpha } \\
\hline $1991-1999$ & 0.000 & $-2.50 \%$ & $-3.31 \%$ & $-4.57 \%$ & $-4.91 \%$ & $3.45 \%$ & $3.53 \%$ & $3.67 \%$ & $4.18 \%$ \\
\hline $2000-2008$ & 0.000 & $-2.07 \%$ & $-3.61 \%$ & $-5.04 \%$ & $-6.84 \%$ & $2.20 \%$ & $2.11 \%$ & $2.05 \%$ & $1.98 \%$ \\
\hline $1991-2008$ & 0.000 & $-2.12 \%$ & $-3.13 \%$ & $-4.24 \%$ & $-5.38 \%$ & $2.26 \%$ & $2.11 \%$ & $2.28 \%$ & $2.44 \%$ \\
\hline
\end{tabular}

The irrelevance of firm size for pricing global fundamental-weighted indexes is illustrated in Figure 1, where the cost-adjusted returns and the standard deviations of the size indexes are plotted against the capital market line (CML) under the notion of modern portfolio theory over the examination period. The relative positions of the fundamental-weighted indexes with different degrees of portfolio concentration are not distinguishable. On the other hand, the cap-weighted indexes that are least concentrated (CAP200) is least affected by the capitalization drag relative to more concentrated cap-weighted indexes.

Figure 2 plots the size indexes against the security market line (SML) under the notion of the capital asset pricing model (CAPM) in terms of their respective cost-adjusted returns and beta coefficients. Once again, the relative positions of the fundamental-weighted indexes cannot be distinguished while the strong positive relationship between the performance of the cap-weighted indexes and the degree of portfolio concentration is detected in this diagram. Using the beta coefficient as the relevant measure of risk for the size indexes, the fundamental indexes are exposed to lower risk but earn higher returns compared to the MSCI World Index. The fact that the fundamentalweighted indexes plot above both the CML and the SML and the cap-weighted indexes plot below both the CML and the SML provide strong evidence that fundamental-weighted indexes are more mean-variance efficient compared to the cap-weighted indexes. 


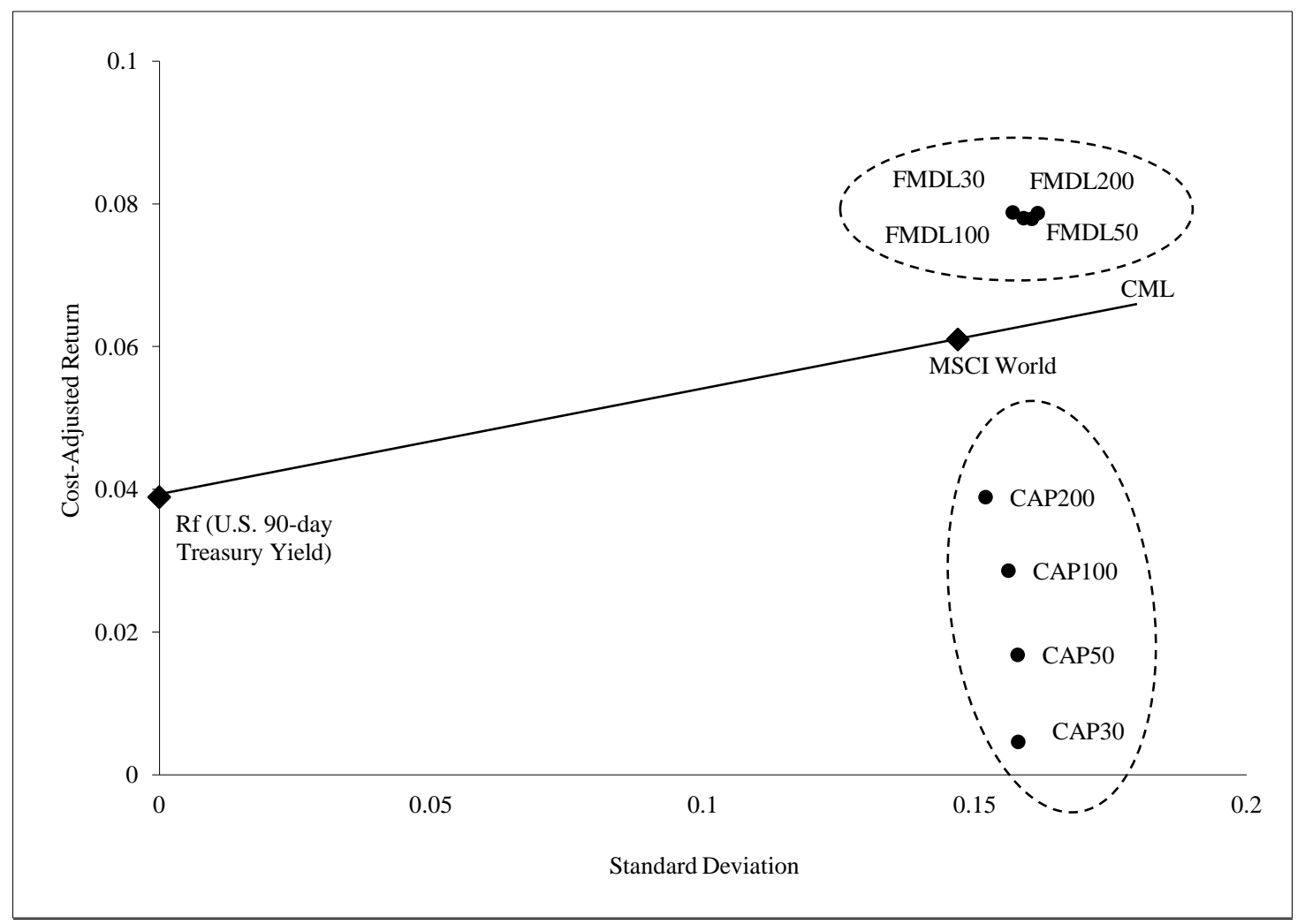

Figure 1: Performance of the Size Indexes against the Capital Market Line (CML)

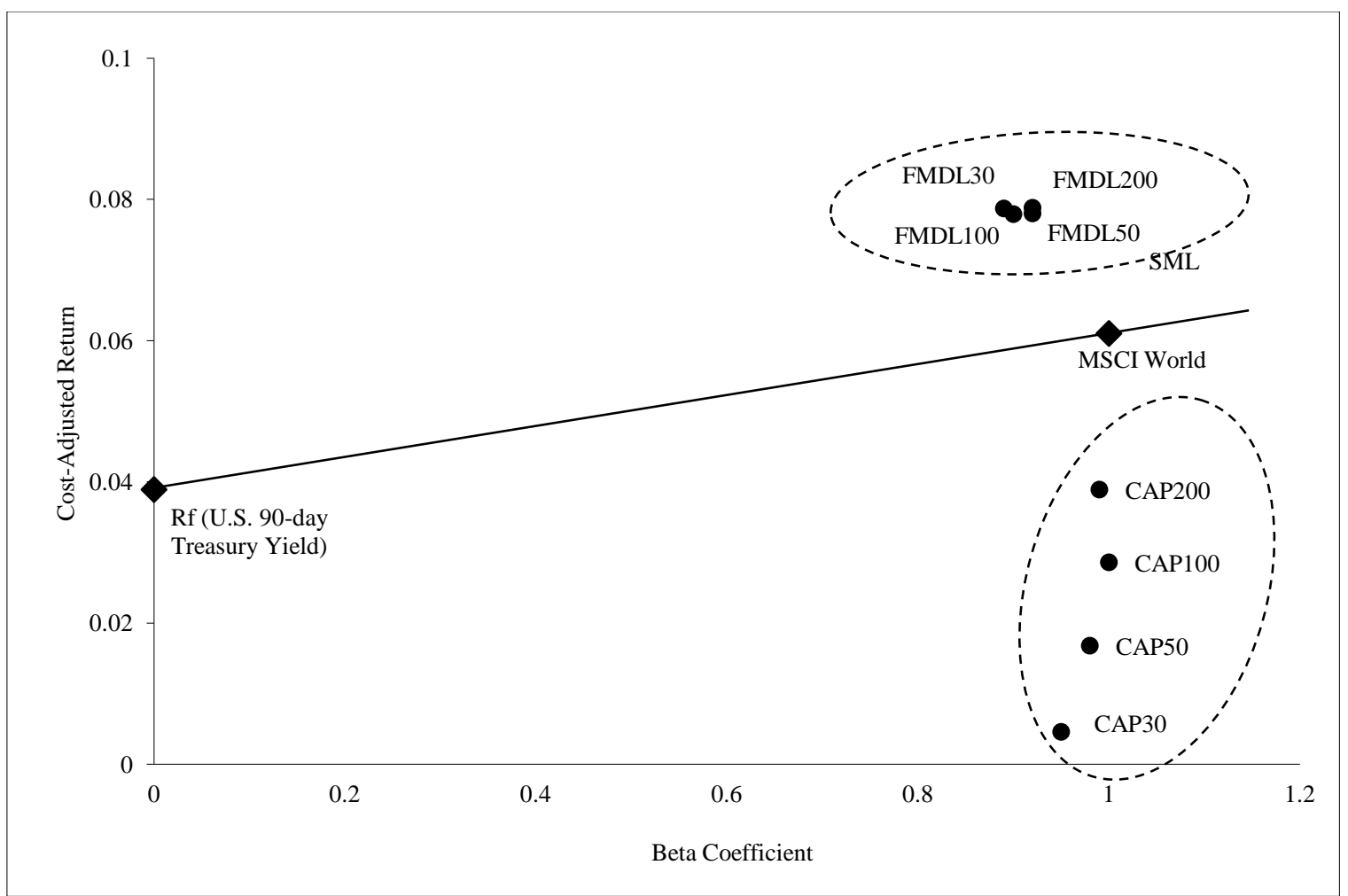

Figure 2: Performance of the Size Indexes against the Security Market Line (SML) 


\section{CONCLUSION}

We compare and contrast the performances of the fundamental-weighted indexes and the cap-weighted indexes of different degrees of concentration from global equities over an 18-year period and two sub-periods. The fundamental-weighted indexes outperform their counterpart cap-weighted indexes and the MSCI World Index on a risk-adjusted basis over all examination periods. By contrast, the cap-weighted indexes underperform the MSCI World Index over all examination periods on a risk-adjusted basis. The underperformance of the cap-weighted indexes is more severe during the market contraction over the second sub-period. This finding implies that acquiring stocks each time the prices rebound in a downward trend will only deepen the losses. The small firm effect is apparent among the cap-weighted indexes. By including more firms with relatively smaller caps in the indexes, the cap-weighted indexes that are less concentrated outperform the cap-weighted indexes that are more concentrated on a risk-adjusted basis. The size effect, however, is not detected amongst the fundamental-weighted indexes that are constructed from price-insensitive attributes. By removing the price-element in measuring firm size, the small firm anomaly is not present in the fundamental-weighted indexes. The fundamental indexes of different degrees of portfolio concentration provide similar risk-return characteristics over the examination periods.

The evidence that the fundamental-weighted indexes earn higher returns with moderate standard deviation and below average beta coefficient supports the proposition for the use of fundamental indexation as proxies for large established firms in the global equity market. The resilient nature of the fundamental indexes during the turbulent post-millennium time period supports the argument of Siegel (2003) that fundamental indexation provides investors protection against the impact of speculative bubbles as the weights of its constituents do not increase with prices unless it is fundamentally justifiable. We recommend the performance analysis of other style-based indexation for global equities as areas requiring further research.

\section{ACKNOWLEDGEMENT}

This work is supported by the National Research Foundation (NRF) of South Africa. The support from the research office of the University of the Western Cape is much appreciated.

\section{AUTHOR INFORMATION}

Dr. Heng-Hsing Hsieh, CFA is the Head of Finance in the School of Business and Finance at the University of the Western Cape, South Africa. He is a CFA charterholder and a member of the South African Institute of Financial Markets (SAIFM). E-mail: ahsieh@uwc.ac.za. Corresponding Author.

Dr. Kathleen Hodnett is currently a Research Fellow (funded by the National Research Foundation (NRF) of South Africa) in the School of Business and Finance at the University of the Western Cape, South Africa. She is a member of the International Institute of Forecasters (IIF) and an associate member of the South African Institute of Financial Markets (SAIFM).

Prof. Paul van Rensburg is the Frank Robb Professor of Finance at the University of Cape Town, South Africa. He is the principal of Salient Quantitative Investment Management. E-mail: paul.vanrensburg@uct.ac.za.

\section{REFERENCES}

1. Amenc N, Goltz F and Le Sourd V (2006), “Assessing the Quality of Stock Market Indices", EDHEC Publication

2. Arnott R D (2005), “Criticism on Market-Cap Indexation”, Editor’s Corner, Financial Analysts Journal, $10-14$

3. Arnott R D, Hsu J and Moore P (2005), "Fundamental Indexation”, Financial Analysts Journal, vol. 61, no 2, 83-99

4. Arnott R D and West J M (Fall 2006), "Fundamental Indexes: Current and Future Applications", Institutional Investor's $5^{\text {th }}$ Annual Exchange-Traded Funds Review, 111-121 
5. Basu S (1977), "The Investment Performance of Common Stocks in Relation to Their Price to Earnings Ratio: A Test of the Efficient Markets Hypothesis", Journal of Finance, vol 32, no 3, 663-682

6. Bauman C, Conover C M and Miller R E (1998), "Growth versus Value and Large-Cap versus Small-Cap Stocks in International Markets”, Financial Analysts Journal, vol. 54, no 2, 75-89

7. Blume M and R Stambaugh (1983), "Biases in Computing Returns: An Application to the Size Effect", Journal of Financial Economics, vol. 28, 19-33

8. Bradfield D J, Barr G D and J F Affleck-Graves (1988), “Asset Pricing in Small Markets- The South African Case", South African Journal of Business Management, vol. 19, no 1, 11-21

9. Brown P, Kleidon A W and Marsh T A (1983), "New Evidence on the Nature of Size-Related Anomalies in Stock Prices", Journal of Financial Economics, no 12, 33-56

10. Chopra N, Lakonishok J and Ritter J R (1992), "Measuring Abnormal Performance - Do Stocks Overreact?", Journal of Financial Economics, no 31, 235-268

11. Christopherson J A and Williams C N (1997), "Equity Style: What It is and Why It Matters", The Handbook of Equity Style Management, edited by Coggin T D, Fabozzi F J and Arnott R D, New Hope, Frank J. Fabozzi Associates, Pennsylvania, 1-19

12. Estrada J (2006), "Fundamental Indexation and International Diversification”, Journal of Portfolio Management, vol. 34, no 3, 93-109

13. Fama E F and French K R (1993), "Common Risk Factors in the Returns on Stocks and Bonds", Journal of Financial Economics, vol 33 no 1, 3-56

14. Hodnett K (2010), "Analysis of the Cross-Section of Equity Returns on the JSE Securities Exchange based on Linear and Nonlinear Modeling Techniques", Unpublished Doctoral Thesis, University of Cape Town

15. Hsieh H (2010), "Applications of Global Equity Style Indices in Active and Passive Portfolio Management", Unpublished Doctoral Thesis, University of Cape Town

16. Hsu J C (2006), “Cap-Weighted Portfolios are Sub-Optimal Portfolios”, Journal of Investment Management, vol. 4, no 3, 1-10

17. Hsu J C and Campollo C (2006), "New Frontiers in Index Investing: An Examination of Fundamental Indexation", Journal of Indexes, 32-38

18. Kaplan P D (2008), "Why Fundamental Indexation Might- or Might Not- Work", Financial Analysts Journal, vol. 64, no 5, 32-39

19. Siegel L B (2003), "International Equity Benchmarks", The Research Foundation of AIMR 